\title{
A cost-effectiveness analysis of the Incredible Years parenting programme in reducing childhood health inequalities
}

\author{
Donal O’Neill · Sinéad McGilloway • \\ Michael Donnelly • Tracey Bywater • \\ Paul Kelly
}

Received: 22 July 2010/ Accepted: 20 July 2011/Published online: 19 August 2011

(c) Springer-Verlag 2011

\begin{abstract}
Early onset of behavioural problems has lasting negative effects on a broad range of lifetime outcomes, placing large costs on individuals, families and society. A number of researchers and policy makers have argued that early interventions aimed at supporting the family is the most effective way of tackling child behaviour problems. This study forms the economic component of a randomised evaluation of the Incredible Years programme, a programme aimed at improving the skills and parenting strategies of parents of children with conduct problems. Our results show that the programme provides a cost-effective way of reducing behavioural problems. Furthermore, our cost analysis, when combined with a consideration of the potential long-run benefits, suggests that investment in such programmes may generate favourable long-run economic returns.
\end{abstract}

D. O’Neill $(\bowtie)$

Department of Economics, NUI Maynooth,

Ireland and Research Fellow IZA, Bonn, Germany

e-mail: donal.oneill@nuim.ie

S. McGilloway · P. Kelly

Department of Psychology, NUI Maynooth,

Maynooth, Ireland

M. Donnelly

Epidemiology and Services Research Group,

School of Medicine, Queens University Belfast,

Belfast, Northern Ireland, UK

T. Bywater

Institute for Effective Education,

University of York, York, UK

T. Bywater

Bangor University, Wales, UK
Keywords Childhood health · Cost-effectiveness analysis - Cost-benefit analysis · Parenting strategies . Randomised controlled trial

JEL Classification $\mathrm{I} 14 \cdot \mathrm{J} 13$

\section{Introduction}

Conduct problems are the most common of childhood mental health difficulties [1], and recent evidence suggests that this problem is becoming more widespread [2]. Data from the Growing up in Ireland Study indicate that 7-8\% of 9-year-olds in Ireland experience abnormal emotional and conduct problems. Such problems involve a range of oppositional or antisocial behaviour such as disobedience, lying fighting and stealing. In some cases, the severity and persistence of the problem is sufficient to warrant a psychiatric diagnosis of 'conduct disorder'. However, research has shown that the adverse consequences of conduct problems are large and persistent even with sub-threshold levels of conduct problems [3]. Among the negative effects associated with conduct problems are poorer educational attainment [4-12], increased criminal activity [10, 13-16], reduced labour market success $[11,12,15,17,18]$ and poorer adult mental health [19]. Consequently, early behavioural problems place large costs on individuals, families and society.

Research on the causes of conduct problems has identified a number of risk factors [20]. These include socioeconomic factors, such as family poverty and deprived neighbourhoods, parental characteristics, such as low education and mental illness, and family relationships, such as abuse and inconsistent or neglectful parenting. Not all risk factors are of equal importance, and evidence suggests 
that early family relationships and parenting style are particularly significant forces [21, 22]. In addition, interventions focused on changing parenting style can offer an effective and economically efficient way of identifying and managing the risks associated with childhood conduct problems [23, 24]. Research supports the efficacy of such programmes in reducing the intensity of conduct problems, both in the short term [25-28] and in the longer term $[15,29,30]$. A systematic overview of the economic evidence on the effectiveness of parenting programmes is given by Charles et al. [31]. Importantly, this review highlights the lack of economic evaluations of parenting programmes, from either a cost-effectiveness or a costbenefit perspective.

This paper contributes to this literature by conducting both an incremental cost-effectiveness analysis of the Incredible Years (IY) parenting programme in Ireland and a long-term cost-benefit analysis.

\section{Methods}

Objective and plan

The objective of this study is to examine the cost-effectiveness of the IY parenting programme in reducing childhood conduct problems in Ireland. Cost-effectiveness is assessed by relating the differential cost per treatment and control group to the differential effectiveness of the programme. Uncertainty is examined using probabilistic sensitivity analysis and presented as cost-effectiveness acceptability (CEA) curves. The results from this analysis are combined with data from secondary sources to provide indirect measures of the long-run rate of return to the IY programme.

\section{The intervention}

The IY parent, teacher and child training series was developed at the University of Washington over the last 30 years and is specifically designed to prevent and treat emotional and behavioural difficulties in children aged 0-12 years. This paper considers the BASIC Preschool/ Early School Years Parent Training component of the programme, which targets children between the ages of 3 and 7 years. Parent competences are developed in areas such as communication, limit setting, problem-solving and anger management. Parents are also encouraged to develop support networks. Two trained facilitators take parents in groups of approximately 12 for one 2 -h session each week over a 12- to 14-week period. The programme uses a collaborative approach between group leader and parents including the analysis of video vignettes of family behaviour for discussion.

\section{Study design}

The outcome study identified a sample of 149 families to take part in the randomised trial [32]. The trial was carried out in typical community-based services in Ireland located in four urban areas, all of which were designated as socioeconomically disadvantaged. Families were recruited to the study using existing community service systems such as Health Board waiting lists and local schools. At baseline, all eligible children had to score over the clinical cut-off on either the Intensity or Problem subscales of the Eyberg Child Behaviour Inventory (ECBI) [33]. The ECBI was also the primary outcome measure of child problem behaviour in our analysis. The ECBI is a parental report of the frequency and intensity of problem behaviour in children and was developed as a screening instrument for the differentiation of normal and conduct problem children [33]. The administration of parental questionnaires is often the first step in the diagnosis of child mental health conditions. The test is used to assess 36 individual problems, including difficulty following orders, difficulty interacting with other children, problems with attention seeking and problems with concentration and attention span. Many of these characteristics have been identified by teachers as important determinants of readiness to learn [34, 35]. The final ECBI test score, which ranges from 36 to 252, is an aggregate of the scores over individual problems. The clinical cut-off for serious behavioural problems with the ECBI is 127.

Sample members were randomly allocated, on a 2:1 basis, to either the parent training intervention group (T) who participated in the programme or a control group (C) who was placed on a waiting list for the intervention (offered after 6-month follow-up). Participants were assessed at baseline in early 2008 , before they received the intervention, and again 6 months later by which time all members of the treatment group had participated in the programme. Of the original sample, 12 failed to respond to the follow-up survey and 5 more families failed to provide adequate data on the ECBI and/or service use. We exclude these observations from the analysis. One could impute values for the missing [36]. However, almost all imputation techniques rely on the assumption that the data are 'Missing at Random'. Under this assumption, the complete case approach adopted here provides consistent estimates, though imputation may lead to efficiency gains. However, the efficiency properties of the imputation approach are based on asymptotic theory, which may not be appropriate given our sample sizes. Excluding the missing data resulted 
Table 1 Demographic statistics by treatment group status

\begin{tabular}{llll}
\hline & $\begin{array}{l}\text { Control } \\
\text { group }\end{array}$ & $\begin{array}{l}\text { Treatment } \\
\text { group }\end{array}$ & $\begin{array}{l}P \text {-value for equality } \\
\text { across treatment } \\
\text { and control groups }\end{array}$ \\
\hline Proportion of children that are male & .72 & .58 & .14 \\
Mother's age & 35 & 34 & .65 \\
Proportion of mothers married & .49 & .34 & .13 \\
Proportion of mothers separated/divorced & .03 & .12 & .09 \\
Proportion of mothers single & .26 & .20 & .51 \\
Proportion of mothers living in social housing & .38 & .35 & .75 \\
Proportion of mothers employed & .23 & .26 & .74 \\
Proportion of mothers with ethnicity reported as white & .85 & .91 & .25 \\
Child's Eyberg intensity score at baseline & 161 & 157 & .51 \\
\hline
\end{tabular}

in a valid sample of 132 parents, of which 93 were members of the treatment group and 39 were members of the control group. ${ }^{1}$ Of the 93 treatment group members, 7 were assigned to treatment but did not complete the programme. These families are nevertheless included in our analysis, and as such, our results should be interpreted on the basis of the intention-to-treat principle. To examine the robustness of our findings to this choice, we also report results based on the smaller sample of compliers.

\section{Cost data}

For purposes of conducting the cost analysis, an adapted version of the Client Service Receipt Inventory (CSRI) was used to record the frequency with which health, educational and social services were used by parents and their children during the previous six months [38]. The CSRI was administered by means of a face-to-face interview with the main caregiver at two time points: at baseline, before parent/caregivers began the parenting course and again 6 months later. In a previous study, much of the unit cost data for services could be obtained from official annual government publications [39]. The Irish government does not publish such a detailed description of unit costs. For this study, data on unit costs were obtained from a variety of sources and agencies. Table 1 lists the key health services for children in Ireland and the corresponding unit costs. For some categories (e.g. general practitioner (GP) visits), the costs are well-established. For others (e.g. A\&E, outpatient and overnight stay in paediatric hospital), costs were obtained from the Casemix/HIPE unit of the Health Service Executive, the organisation charged with running

\footnotetext{
1 These relatively small sample sizes reflect the specific nature of the underlying population and are not unusual in studies of this nature (see for example Table 2.3 [37]. In addition, our findings show that the sample sizes we use are sufficient to precisely estimate the key parameters of our model.
}

the public health system in Ireland. ${ }^{2}$ For other services (e.g. special needs assistants (SNAs)), official government payscales were used to determine an hourly rate for the service.

In addition to the service costs, we also collected data on the direct recurrent costs per parent of running the programme. These costs were obtained from 'cost diaries' completed by each of the group facilitators during each week of the programme. These costs covered the full range of recurrent costs involved in implementing the programme. These included (1) costs of recruiting the parents to the group; for instance, time and mileage for each family visited and telephone call; (2) costs directly related to ongoing group (e.g. session preparation time, home visits to parents and supervision time); and (3) costs incurred through facilities provided, such as the provision of crèche facilities or payment for childcare, taxis, food and catering, and other administrative costs directly related to the programme. Non-recurrent initial training and group set-up costs were not included for purposes of this analysis. A total of 18 cost diaries were completed covering all facilitators.

\section{Results}

Demographic characteristics

At the start of our study, each parent completed a Profile Questionnaire that collected detailed information on family background, employment status and income levels. Summary statistics, by treatment status, for the sample used in this study are given in Table 2. As expected, given randomised allocation between groups, there are no

\footnotetext{
${ }^{2}$ We are grateful to Fiachra Bane, CASEMIX/HIPE analyst at the HSE, for providing these figures. More information on the Irish Casemix system can be found at http://www.casemix.ie/.
} 
Table 2 Unit costs data for service use

\begin{tabular}{ll}
\hline Service & Unit cost (Source) \\
\hline GP & $€ 45$ \\
Nurse & $€ 24$ an hour (estimate based on Department of Health \& Children Payscales for Public Health Nurse) \\
Speech therapist & $€ 22.11$ an hour (estimate based on Department of Health \& Children Payscales) \\
Physiotherapist & $€ 22.11$ an hour (estimate based on Department of Health \& Children Payscales) \\
Social worker & $€ 19.23$ an hour (estimate based on Department of Health \& Children Payscales for Social Care Worker) \\
Community paediatrician & $€ 24$ \\
SNA & $€ 15.20$ an hour (estimate based on Department of Education Payscales for SNA) \\
Casualty department (A\&E) & $€ 273$ (Department of Health Casemix/HIPE Unit—direct correspondence) \\
Travel by ambulance & $€ 83$ (Department of Health) \\
Outpatient consultant appointment & $€ 160$ (Department of Health Casemix/HIPE Unit—direct correspondence) \\
Overnight stay in hospital & $€ 1,562$ (Department of Health Casemix/HIPE Unit—direct correspondence) \\
\hline
\end{tabular}

Fig. 1 Density of Eyberg intensity scores at baseline and 6-month follow-up for treatment and control groups
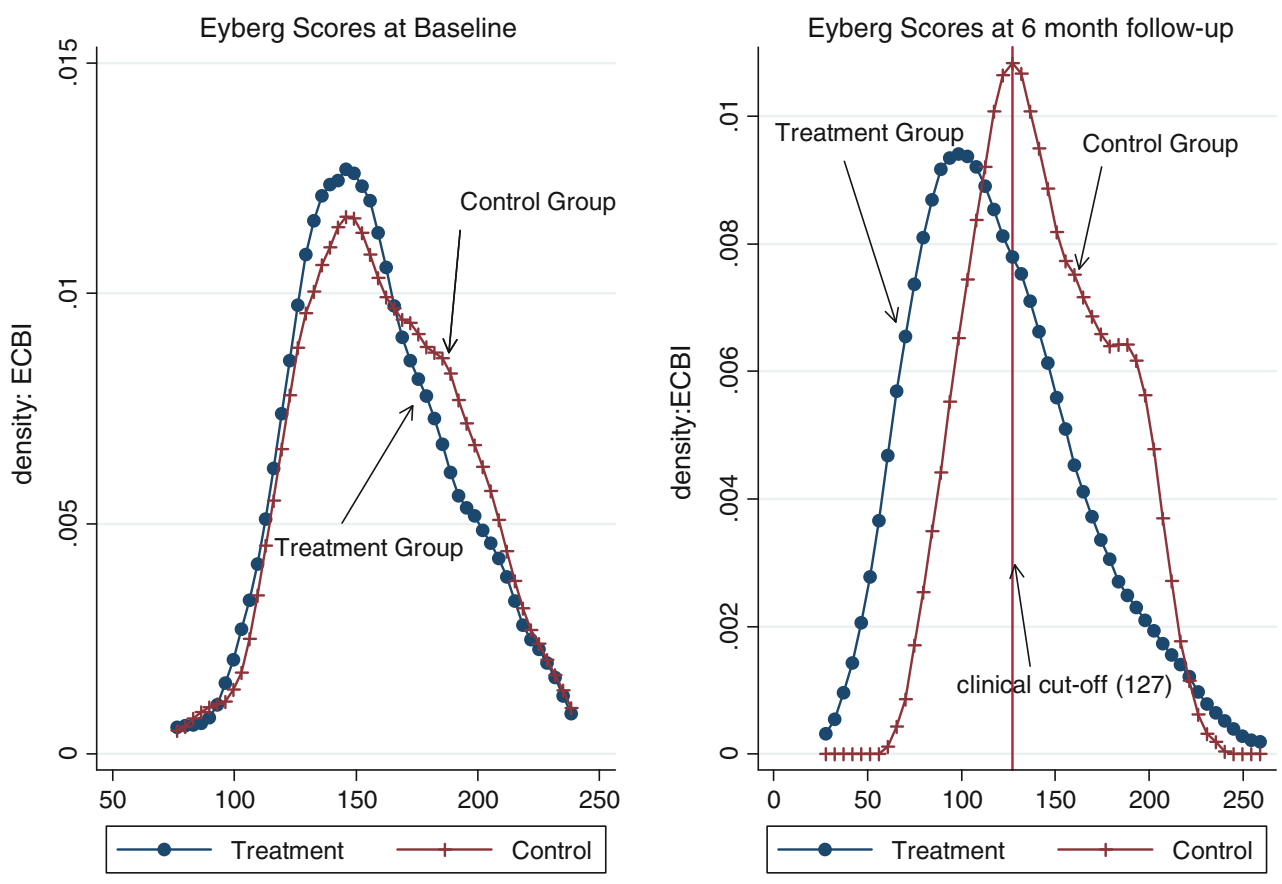

significant differences in the demographic characteristics of the families or the pre-intervention ECBI score across groups.

Impact of programme on child behaviour

Figure 1 shows the full distribution of pre- and postintervention ECBI scores for both the treatment and control groups in our sample. The left-hand panel of this figure confirms the similarities in the distribution of test scores prior to the intervention. The right-hand panel, in contrast, shows a significant shift in the distributions post-treatment. In particular, the mean difference in the ECBI test between treatment and control groups post-treatment is $20.33 .^{3}$ This compares with the estimate of 21 reported by McGilloway et al. [32] using a slightly larger sample in which missing data were imputed. The distributions in Fig. 1 show that this mean effect is not driven by outliers and instead reflects a genuine improvement in test scores throughout the sample. Significantly more of the treatment group had obtained ECBI scores below the clinical cut-off following the intervention $(60 \%$ for the treatment group vs. $35 \%$ of the control group).

\footnotetext{
3 The estimate is based on a difference-in-difference approach that adjusts for differences in baseline values of the test score.
} 
Table 3 Proportion using medical services at baseline and follow-up survey

\begin{tabular}{|c|c|c|c|c|c|c|}
\hline Service & $\begin{array}{l}\text { Control } \\
\text { baseline }(\%)\end{array}$ & $\begin{array}{l}\text { Treatment } \\
\text { baseline }(\%)\end{array}$ & $\begin{array}{l}\text { Control } \\
\text { follow-up (\%) }\end{array}$ & $\begin{array}{l}\text { Treatment } \\
\text { follow-up }(\%)\end{array}$ & $\begin{array}{l}P \text {-value for equality } \\
\text { over time, control }\end{array}$ & $\begin{array}{l}P \text {-value for equality } \\
\text { over time, treatment }\end{array}$ \\
\hline GP & 51 & 65 & 56 & 49 & .57 & .02 \\
\hline Nurse & 15 & 9 & 8 & 5 & .26 & .41 \\
\hline Speech therapist & 21 & 22 & 18 & 15 & .74 & .06 \\
\hline Physiotherapist & 3 & 7 & 5 & 2 & .32 & .10 \\
\hline Social worker & 5 & 10 & 10 & 1 & .32 & .004 \\
\hline Community paediatrician & 3 & 4 & 0 & 3 & .32 & .70 \\
\hline SNA & 20 & 14 & 13 & 13 & .26 & .78 \\
\hline Casualty department (A\&E) & 8 & 14 & 13 & 14 & .32 & 1 \\
\hline Outpatient consultant appointment & 10 & 18 & 21 & 15 & .10 & .53 \\
\hline Overnight stay in hospital & 3 & 6 & 3 & 8 & 1 & .71 \\
\hline
\end{tabular}

Service usage and recurrent costs

The details on service use are given in Table 3. In terms of primary care, the most commonly used services were GPs, nurses and speech therapists. ${ }^{4}$ The remaining primary care services such as social workers, paediatricians and physiotherapists tended to be used by less than $10 \%$ of either group. In terms of special resources during schooling, only one-to-one help, which is likely to mean accessing SNAs, was a commonly reported service. A statistical analysis of the baseline data showed no significant difference in service use between the control and treatment groups at the start of our analysis.

Looking at the change in service use over time, we see that while there is evidence of a decline in service use by the control group, the reduction is more pronounced for the treatment group. In particular, there is a substantial decline in the use of many primary care services, as well as less contact with social workers for those who received the treatment. To determine whether these differences were statistically significant, we tested the null hypothesis that service use was unchanged between baseline and followup. The $P$-values for this test are given in columns 6 and 7 of Table 3, for the control group and treatment group, respectively. The results show no significant change in service use for the control group. However, members of the treatment group reported significant reductions in the use of a number of services, including GP visits, use of speech therapists and visits to social workers. This decline in

\footnotetext{
${ }^{4}$ Comparisons with the general population are difficult though the proportion of the total adult population in Ireland who had visited a GP at least once in the previous 12 months rose from $70.9 \%$ in 1987 to 85.6 in 2000 for medical card holders (typically low-income families) and from 52.9 to 66.9 for non-medical card holders [40]. And $16.7 \%$ of the adult population had an outpatient visit to a hospital during 2000. The comparative figures for inpatient and A\&E visits were 12.9 and $11.8 \%$, respectively [41].
}

Table 4 Recurrent costs of programme provision using leader cost diaries $(€)$

\begin{tabular}{llll}
\hline & $\begin{array}{l}\text { Total cost of } \\
\text { programme }\end{array}$ & $\begin{array}{l}\text { Average cost } \\
\text { per group }\end{array}$ & $\begin{array}{l}\text { Average cost } \\
\text { per client }\end{array}$ \\
\hline Direct wage costs & $€ 128,321$ & $€ 14,257$ & $€ 1,296$ \\
Other costs & $€ 15,219$ & $€ 1,691$ & $€ 153$ \\
Travel costs & $€ 1,389.5$ & $€ 154$ & $€ 14$ \\
Total & $€ 144,929.5$ & $€ 16,102$ & $€ 1,463$ \\
\hline
\end{tabular}

service use in the treatment group is consistent with improved child behaviour and enhances the overall costeffectiveness of the programme.

Table 4 provides a summary of recurrent costs. For simplicity, we summarise these costs in three categories: direct wage costs covering the costs of the facilitators time, travel costs and other costs and expenses. As expected, direct wage costs constituted the largest component of total cost, accounting for almost 90\%. Additional expenses accounted for the majority of the remaining costs, with travel expenses amounting to a minor component of overall costs. Since the average group size observed in this study was 11 parents per group, these data imply an average recurrent cost per parent of $€ 1,463$.

Table 5 combines these data with the service utilisation costs to estimate the incremental costs associated with the programme. The final row indicates that the additional net cost of the programme was approximately $€ 1,759.74$. This figure is used to construct an estimate of the overall costeffectiveness of the programme.

\section{Cost-effectiveness of IY parenting programme}

When the data on outcomes and costs are combined, we estimate an incremental cost-effectiveness ratio of $€ 87$ per 1 point reduction in the Eyberg intensity score 
Table 5 Health social care and special education services used by children

\begin{tabular}{llllll}
\hline Type of service & \multicolumn{2}{l}{ At baseline } & & \multicolumn{2}{l}{ At 6-month follow-up } \\
\cline { 2 - 3 } & Control & Treatment & & Control & Treatment \\
\hline Primary care & 110.78 & 136.51 & 106.6 & 110.56 \\
Hospital services & 148.13 & 371.49 & 197.56 & 229.10 \\
Special education & 830.93 & 523 & 438.46 & 665.66 \\
Social services & 2.96 & 7.24 & 20.71 & 0 \\
Parenting programme & None & None & None & 1,463 \\
Total & $1,092.81$ & $1,038.24$ & 763.34 & $2,468.52$ \\
Change in cost over 6 months & & & -329.47 & $1,430.27$ \\
Net change in cost & & & & $1,430.27+329.47=1,759.74$ \\
\hline
\end{tabular}

Figures are mean total cost per child $(€)$

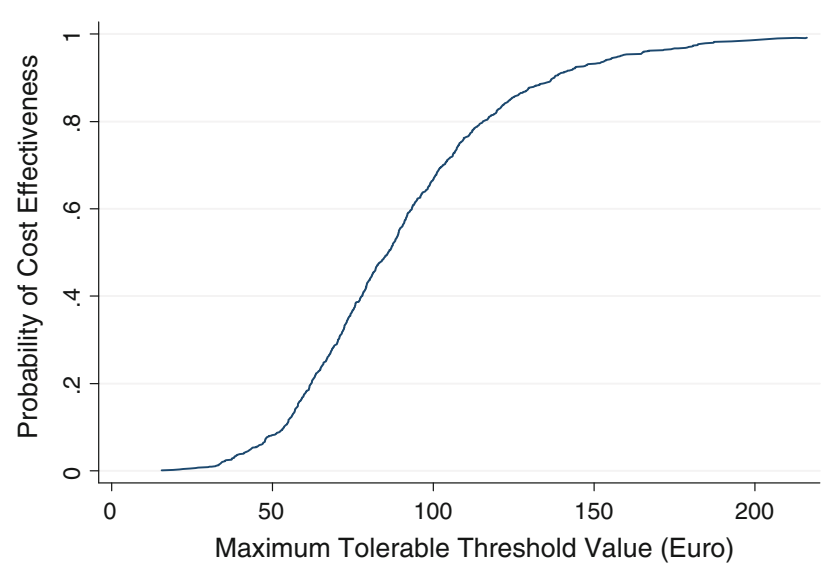

Fig. 2 Cost-effectiveness acceptability curve for IY evaluation

$(1,759.74 / 20.33),{ }^{5}$ with a $90 \%$ bootstrapped confidence interval of [€43-€158]. This estimate compares to the point estimate of $£ 73$ (€83) obtained in the cost-effectiveness study of the IY programme in Wales [39]. Using our estimate, it would cost $€ 9,483((235-126) * 87)$ to bring the child with the highest intensity score to below the clinical cut-off point and $€ 2,784((158-126) * 87)$ to bring the average child in the study below this limit.

The probabilistic results are summarised in the CEA curve and the cost-effectiveness plane shown in Figs. 2 and 3 , respectively. Given uncertainty about the parametric distribution of the ICER, we use a 1,000 replication bootstrap to estimate the CEA. From Fig. 2, we infer that the probability of the IY programme being cost-effective would exceed $90 \%$ provided the willingness to pay threshold was at least $€ 137$. This probability falls to $80 \%$ if the threshold is reduced to $€ 115$ and rises to $95 \%$ if the threshold increases to $€ 158$.

\footnotetext{
5 The estimated ICER using compliers only is slightly lower at $€ 76$. This reflects a smaller reduction in the ECBI score among the 7 families assigned to the IY intervention but who dropped out before completing the programme.
}

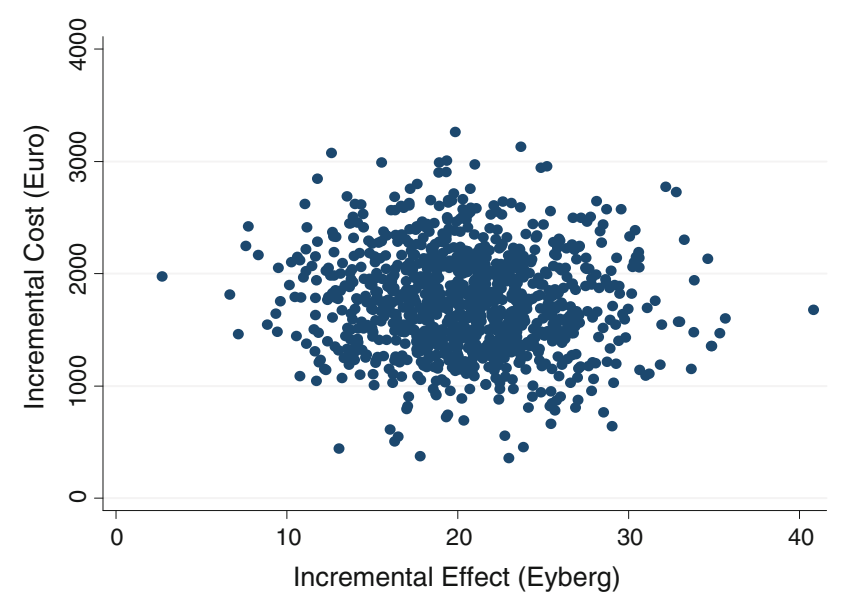

Fig. 3 Cost-effectiveness plane for IY evaluation

Cost-benefit implications

To date, there have been very few cost-benefit analyses of early intervention programmes of the type considered in this paper. Aos et al. [42] undertook a series of cost-benefit analyses for a range of early intervention programmes. ${ }^{6}$ Their results for Pre-Kindergarten Education Programmes and Home Visitation Programmes indicate that while some programmes (such as Nurse-Family Partnership for LowIncome Women and Home Visitation Programmes for At-Risk Mothers and Children) achieve significantly higher benefits than costs, others (e.g. Early Head Start, Comprehensive Child Development Programme and Infant Health and Development Programme) were less successful in this respect, yielding net losses of between $\$ 16,203$ and $\$ 49,000$ per youth.

While many of the programmes discussed by Aos et al. have features in common with the IY programme, this programme itself was not included on the grounds that the outcomes associated with the programme (i.e. reductions in

${ }^{6}$ For reviews of this and other cost-benefit studies, see [37, 43, 44]. 
child conduct disorder) are difficult to value. While we accept that this is difficult, we nevertheless believe that there is merit in trying to use the results from the costeffectiveness analysis to determine a longer-run rate of return for the IY programme.

\section{Cost-benefit analysis of IY programme}

To carry out the cost-benefit analysis of the IY programme, we combine the results from our cost-effectiveness analysis with estimates of the effect of conduct problems on key outcomes in adult life. For pragmatic reasons, we focus on three outcomes: education, crime and unemployment. There is an extensive literature of the effects of conduct problems on each of these outcomes, and in addition, it may be possible to assign monetary values to the associated gains using secondary data sources.

There is a substantial body of research showing that early conduct problems have a negative effect on educational attainment [4-12]. In particular, children with conduct problems were more likely to require remedial help at primary and secondary school, were more likely to have to repeat a grade, performed less well on exams and were less likely to obtain recognised educational qualifications. To capture these effects in our cost-benefit analysis, we assume that the educational cost of children with conduct problems amounted to an additional-hour-a-week contact with a SNA for each of the first 4 years of primary school. Given a school year of 37 weeks and an hourly pay rate of $€ 15.20$ for SNA, this translates into an annual savings of $€ 562.40$ per year. In our 'Discussion' section, we consider a broader measure of this educational effect.

There is also evidence of a significant link between conduct problems and criminal activity [10, 13-16]. The report by the Sainsbury Centre for Mental Health estimates that around $80 \%$ of all criminal activity is attributable to people who had conduct problems in childhood and adolescence [14]. Children with conduct problems were more likely to have engaged in criminal activity, more likely to have been arrested and more likely to have spent time in jail. Friedli and Parsonage estimate that the overall lifetime costs of crime was $€ 182,262$ per case for those with conduct disorder in the UK and $€ 51,250$ per case for those with mild conduct problems [45]. Fergusson et al. [13] estimated that the gap in the probability of imprisonment between those with behavioural problems and those without was $7 \%$ points. $^{7}$ Figures for Ireland suggest that the average cost of keeping a prisoner for the year 2007 was $€ 97,700$ [46]. This figure gives an approximate measure of the additional cost of prison of the order of $€ 6,839$ per

\footnotetext{
7 This is also close to the mid-point of the range of estimates reported by Koning et al. [10].
}

person. In our conservative calculations, we assume that the savings from reductions in imprisonment occur only once and at the age of 30 , which is the average age of the prison population in Ireland in 2007 [46].

Finally, evidence of an association between conduct problems and poor adult labour market performance is provided in a number of studies [11, 12, 15, 17, 18]. In our initial analysis, we consider only the effect of higher unemployment, though potential wage losses are discussed later. We assume that individuals with conduct problems spend an additional 5 months in unemployment. This is consistent with the range of estimates reported in Moffitt et al. [18] who followed individuals up until age 26. It is estimated that the annual cost of unemployment in Ireland, in terms of welfare payments and losses in taxes, is approximately $€ 15,000$ which, when combined with unemployment effect, leads to an expected savings of $€ 6,250$. Again, we make the conservative assumption that that this is a once-off saving occurring at the age of 30 .

The pre-intervention mean ECBI score for members of our sample was 158 . Thus, a 32-point decrease is required to reduce this score below the critical level. When combined with our estimated incremental cost-effectiveness ratio, this means the cost of bringing the average problem child below the clinical cut-off is $€ 2,784$. Combing these cost and benefit data yields an internal rate of return for the programme of $11 \% .^{8}$

\section{Sensitivity analyses}

To examine the sensitivity of our estimated returns, we consider alternative valuations for the crime and unemployment effects, and for our cost estimates. For crime, we consider both a $2 \%$ point gap and a $14 \%$ point gap in imprisonment rates. These span the range of estimates reported in Koning et al. [10]. With these estimates, the internal rate of return ranges from 9 to $12 \%$. To consider the sensitivity of our results to the valuation of unemployment, we consider savings based on both a 1-month and a 1-year reduction in unemployment. Since our estimated unemployment effect is based on work-histories up until the age of 26 , we also consider a more extreme unemployment effect of 3 years to allow for effects in later years. With these valuations, the internal rate of return ranges from 9 to $17 \%$. When varying our cost estimates, we use the upper and lower bounds of our $90 \%$ confidence interval reported earlier (€43-€158). Costs of these magnitude lead to returns of 6 and 25\%, respectively. Finally,

\footnotetext{
${ }^{8}$ Sometimes investments are summarised using net present values (NPV) rather than internal rate of returns. Assuming an opportunity cost of capital of $5 \%$, the NPV of the IY program given our assumptions is $€ 2,927$ per child.
} 
we take a rather extreme assumption and assume that the reduction in crime is the only benefit arising from treatment of conduct disorder. ${ }^{9}$ In this case, the rate of return falls to $4 \%$.

\section{Discussion}

The first objective of this study was to examine the costeffectiveness of the IY parenting programme as a means of tackling conduct problems in young children. In keeping with previous work, we find that the IY programme was cost-effective in reducing conduct problems (with an ICER less than €90). When interpreting these results, it is important to bear in mind the short-run nature of the analysis presented here. In this study, we only followed participants for 6 months after the treatment. While we know of no long-run randomised evaluation of the IY programme, the evidence available does suggest that the initial gains reported for the IY programme may have a significant longer-run component. Hutchings et al. [48] report on a 4-year follow-up evaluation of a structured parenting programme, which is similar in many ways to the IY programme. They found that the substantial improvements in child behaviour observed after the 6-month follow-up were still evident four years after the intervention had stopped. By contrast, the control group received a less intensive programme but exhibited no evidence of long-run gains. Furthermore, Bywater et al. [30] show that significant improvements in primary measures of child behaviour resulting from an evaluation of the IY parenting programme conducted in Wales were maintained in the medium term (18 months after baseline). In addition, Webster-Stratton, Rinaldi and Reid carried out assessments of participants 8-12 years after contact with the programme [49]. Although no control group was available in this case, the results suggest that the treated children showed less severe conduct problems at adolescence (e.g. limited contact with the criminal justice system) than might have been expected given their earlier clinical levels of conduct disorder.

Using similar methodology, McGilloway et al. [50] report results from a 12-month follow-up of the 103 members of the base treatment group in the current trial. Members of the control group were subsequently offered the intervention and therefore could not be included in the longer-run study. In addition, 16 members of the treatment group were lost to the 12-month follow-up. Nevertheless, these data provide some evidence on the extent to which

\footnotetext{
${ }^{9}$ Savings due to reduced crime constitute the largest component of many existing cost-benefit analyses of early childhood interventions $[15,47]$.
}

the improvement in behaviour identified at 6 months persists. The results suggest that the positive early effects of the IY programme were maintained at the 12-month follow-up, thereby suggesting sustained benefits for children and their families in the longer run.

To estimate the economic rate of return to the IY programme, we combined our cost data with benefit data taken from a variety of sources. Our estimated returns compare favourably with previous evaluations of policies aimed at tacking disadvantage. The estimated internal rate of return of the Perry Preschool Project, perhaps the most heralded early childhood intervention programme in the United States, was $8 \%$ [51], while many of the adult training programmes are reported to have yielded negative returns [52].

The strength of this analysis is heavily dependent on the quality of the data inputs used. Our model is based on multiple data sources: RCT for effectiveness, published data for costing and an array of secondary international sources for the likely effect of conduct problems on adult outcomes. While this is problematic, it is also unavoidable since this is the first paper of its kind that uses Irish data.

While this array of sources is not ideal, the data used are the best available and follow a detailed review of the literature. We focused on three outcomes, education, crime and unemployment, for pragmatic reasons. Data on these outcomes were taken from a range of studies, which avoided relying on one single source. In addition, these outcomes were most easily valued in monetary terms. Other benefits such as improvements in second- and thirdlevel educational attainment and associated increases in productivity and earnings capacity, reductions in substance abuse, decreased teenage pregnancy, benefits to victims of reduced crime and benefits accruing to the parents and/or other siblings as a result of the programme were omitted and are likely to push the estimated returns higher. For example, the OECD report that the net present value to society of completing second-level education in Ireland was approximately $€ 22,000$ [53]. This includes the benefits and costs to both the individual and society. Cleary et al. [16] report a difference in second-level graduation rates in Ireland between those with behavioural problems and those with none of approximately $40 \%$ points. If we use this broader measure to value the educational return of the parenting programme, the estimated net present value of the programme increases from $€ 2,927$ to $€ 9,830$.

These caveats suggest that our estimated long-run returns may be conservative. On the other hand, the shortrun nature of our evaluation leaves open the question as to whether additional programme costs may be needed in the future in order to maintain the short-run benefits identified in our evaluation. In addition, the difficulties associated 
with valuing the benefits of reduced behavioural problems, in the absence of a long-term follow-up, need to be recognised when considering our results.

Finally, in conducting our cost-benefit analysis, it was often difficult to distinguish between private benefits/costs, accruing to the family directly, and public benefits/costs that accrue to society at large. For instance, when costing primary care, we use a rate of $€ 45$ per GP visit. For most families in Ireland, this is paid out of pocket on a fee-perservice basis and is not reimbursed even when the family have health insurance. In this instance, the cost is borne by the family. However, for families who have a medical card-generally because they fall below the income threshold typically in the order of $€ 300$ for families or lone parents - the costs of GP visits are borne by the state and thus reflect a cost to society and not the individual. While primary care costs constituted a relatively small proportion of overall costs in our study, this distinction between private and social gains/cost may be more relevant in other dimensions. When analysing crime, we only consider the savings to the taxpayer from reductions in the prison population, and none of the private benefits that arise from the reduced probability of imprisonment. Further analysis may be useful in distinguishing between private and social benefits/gains though this is likely to prove difficult at present given the format and accessibility of currently available data.

\section{Conclusion}

The call for an increased policy focus on early childhood interventions and in particular policies that tackle the role of the family in early childhood development has been growing in recent years. This call is based on the dual premise that 'skill begets skill', so that early childhood intervention can result in cumulative gains over the life cycle and that the family environment plays a significant role in the development of early childhood behaviour and health. This paper uses the findings from a randomised controlled trial to examine one such early childhood intervention programme. Our findings suggest that the IY programme offers a cost-effective policy option for reducing behavioural problems and in doing so may generate favourable long-run economic returns.

Acknowledgments We gratefully acknowledge the financial assistance provided by Archways Ltd, Ireland, with the support of the Atlantic Philanthropies. We would also like to thank Catherine Byrne, Mark Dynarski, Patricia Del Grosso, Paul Downes, Judy Hutchings, Olive Sweetman, Carolyn Webster-Stratton, members of the Incredible Years Ireland Study team and seminar participants at NUI Maynooth for their helpful comments on this work.

\section{References}

1. National Institute for Health and Clinical Excellence: ParentTraining/Education Programmes in the Management of Children with Conduct Disorders, NICE Technology Appraisal guidance 102, London: NICE (2006)

2. Collishaw, S., Maughan, B., Goodman, B.R., Pickles, A.: Time trends in adolescent mental health. J. Child Psychol. Psychiat. 45(8), 1350-1362 (2004)

3. Almond, D., Currie, J.: Human Capital Development Before the Age of Five. NBER Working Paper 15827 (2010)

4. Gregg, P., Machin, S.: Childhood disadvantage and success or failure in the labour market. In: Blanchflower, D., Freeman, R. (eds.) Youth Employment and Joblessness in Advanced Countries. National Bureau of Economic Research, Cambridge, MA (1999)

5. Currie, J., Stabile, M.: Child mental health and human capital accumulation: the case of ADHD. J. Health Econ. 25(6), 1094-1118 (2006)

6. Currie, J., Stabile, M.: Mental health in childhood and human capital. In: Gruber, J. (ed.) The Problems of Disadvantaged Youth: An Economic Perspective, pp. 115-148. University of Chicago Press, NBER (2007)

7. Case, A., Fertig, A., Paxson, C.: The lasting impact of childhood health and circumstances. J. Health Econ. 24, 365-389 (2005)

8. Fletcher, J., Wolfe, B.: Child mental health and human capital accumulation: the case of ADHD revisited. J. Health Econ. 27, 794-800 (2008)

9. Ding, W., Lehrer, S., Niels, J., Rosenquist, Audrain-McGovern, J.: The impact of poor health on academic performance: new evidence using genetic markers. J. Health Econ. 28, 578-597 (2009)

10. Koning, P., Webbink, D., Vujic, S., Martin N.: The Effect of Childhood Conduct Disorder on Human Capital. IZA DP. No. 4940 (2010)

11. Colman, I., Murray, J., Abbott, R., Maughan, B., Kuh, D., Croudace, T., Jones, P.: Outcomes of conduct problems in adolescence: 40 year follow-up of national cohort. British Med. J. 338a, 2981 (2009)

12. Richards, M., Abbott, R.: Childhood Mental Health and Life Chances in Post-War Britain. Sainsbury Centre for Mental Health, London (2009)

13. Fergusson, D., Horwood, L., Ridder, E.: Show me the child at seven: the consequences of conduct problems in childhood for psychosocial functioning in adulthood. J. Child Psychol. Psychiat. 46(8), 837-849 (2005)

14. Sainsbury Centre for Mental Health: The Chance of a Lifetime: Preventing Early Conduct Problems and Reducing Crime. Policy paper (2009)

15. Scott, S., Knapp, M., Henderson, J., Maughan, B.: Financial cost of social exclusion: follow-up study of antisocial children into adulthood. British Med. J. 323L, 1-5 (2001)

16. Cleary, A., Fitzgerald, M., Nixon, E.: From Child to Adult: A Longitudinal Study of Irish Children and their Families. Government of Ireland/Stat Office/Department of Social and Family Affairs, Dublin (2004)

17. Caspi, A., Enter Wright, B., Moffitt, T., Silva, P.: Early failure in the labor market: childhood and adolescent predictors of unemployment in the transition to adulthood. Am. Sociol. Rev. 63(3), 424-451 (1998)

18. Moffitt, T., Caspi, A., Harrington, H., Milne, B.: Males on lifecourse-persistent and adolescence-limited antisocial pathways: follow up at age 26 years. Dev. Psychopathol. 14, 179-207 (2002) 
19. Odgers, C.L., Caspi, A., Broadbent, J., Dickson, N., Hancox, R., Harrington, H., Poulton, R., Sears, M., Thomson, W., Moffitt, T.: Prediction of differential adult health burden by conduct problem subtypes in males. Arch. Gen. Psychiat. 64, 476-484 (2007)

20. Wasserman, G., Keenan, K., Tremblay, R., Coie, J., Herrenkohl, T., Loeber, R.: Risk and Protective Factors of Child Delinquency. US Department of Justice, Washington DC (2003)

21. Campbell, S.: Behaviour problems in pre-school children: a review of recent research. J. Child Psychol. Psychiat. 36, 113-149 (1995)

22. Dooley, M., Stewart, J.: Family income, parenting styles and child behavioural-emotional outcomes. Health Econ. 16, 145-162 (2007)

23. Brooks-Gunn, J., Markman, L.: The contribution of parenting to ethnic and racial gaps in school readiness. Future Child. 15(1), 139-168 (2005)

24. Bauer, N., Webster-Stratton, C.: Prevention of behavioural disorder in primary care. Curr. Opin. Pediatr. 18, 654-660 (2006)

25. Patterson, J., Barlow, J., Mockford, C., Klimes, I., Pyper, C., Stewart-Brown, S.: Improving mental health through parenting programmes: block randomised controlled trial. Arch. Dis. Child. 87, 472-477 (2002)

26. Gross, D., Fogg, L., Webster-Stratton, C., Garvey, C.W.J., Grady, J.: Parent training with multiethnic families of toddlers in day care in low-income urban communities. J. Consult. Clin. Psychol. 71, 261-278 (2003)

27. Hutchings, J., Bywater, T., Daley, D., Gardner, F., Whitaker, C., Jones, K., et al.: Parenting intervention in sure start services for children at risk of developing conduct disorder: pragmatic randomised controlled trial. British Med. J. 334, 678-682 (2007)

28. Fergusson, F., Stanley, L., Horwood, L.: Preliminary data on the efficacy of the incredible years basic parent programme in New Zealand. Aust. N. Z. J. Psychiat. 43(1), 76-79 (2009)

29. Jones, J., Daley, D., Hutchings, J., Bywater, T., Eames, C. Efficacy of the incredible years programme as an early intervention for children with conduct problems and ADHD: longterm follow-up. Child Care Health Dev. 34(3), 380-390 (2008)

30. Bywater, T., Hutchings, J., Daley, D., Whitaker, C., Tien Yeo, S., Jones, K., Eames, C., Tudor Edwards, R.: Long-term effectiveness of a parenting programme for children at risk of developing conduct disorder. British J. Psychiat. 195, 324-328 (2009)

31. Charles, J.M., Bywater, T., Edwards, R.T.: Parenting interventions: a systematic review of the economic evidence. Child Care Health Dev. (2011). Published online: 6 Mar 2011

32. McGilloway, S., Bywater, T., Ni Mhaille, G., Comiskey, C., Leckey, Y., Kelly, P., Donnelly, M.: Preventing conduct problems through parenting programmes in disadvantaged areas: a pragmatic randomised controlled trial. In submission (2010)

33. Eyberg, S.M., Ross, A.W.: Assessment of child behaviour problems: the validation of a new inventory. J. Clin. Child Psychol. Summer, 113-116 (1978)

34. Lewit, E., Baker, L.: School readiness. Future Child. 5(2), 128-139 (1995)

35. Kiernan, G., Axford, N., Little, M., Murphy, C., Greene, S., Gormley, M.: The school readiness of children living in a disadvantaged area in Ireland. J. Early Child. Res. 6(2), 119-144 (2008)

36. Little, R., Rubin, D.: Statistical Analysis with Missing Data. Wiley and Sons, New Jersey (2002)
37. Karoly, L., Kilburn, M., Cannon, J.: Early Childhood Interventions: Proven Results, Future Promises. RAND Corporation, Washington DC (2005)

38. Beecham, J., Knapp, M.: Costing psychiatric interventions. In: Thornicroft, G., Brewin, C., Wing, J. (eds.) Measuring Mental Health Needs, pp. 179-190. Gaskill, London (1992)

39. Edwards, R., O'Ceilleachair, A., Bywater, T., Hughes, D., Hutchings, J.: Parenting programme for parents of children at risk of developing conduct disorder: cost effectiveness analysis. British Med. J. 334, 682-685 (2007)

40. Madden, D., Nolan, A., Nolan, B.: GP reimbursement and visiting behaviour in Ireland. Health Econ. 14, 1047-1060 (2005)

41. Harmon, C., Nolan, B.: Health insurance and health service utilizations in Ireland. Health Econ. 10, 135-145 (2001)

42. Aos, A., Lieb, R., Mayfield, J., Miller, M., Pennucci, P.: Benefits and Costs of Prevention and Early Intervention Programs for Youth. Olympia, Washington State Institute for Public Policy (2004). Available at http://www.wsipp.wa.gov/rptfiles/04-7-3901. pdf

43. Dretzke, J.E., Frew, C., Davenport, J., Barlow, S., StewartBrown, J., Sandercock, S., Bayliss, J., Raftery,C., Hyde, R., Taylor: The Effectiveness and Cost-Effectiveness of Parent Training/Education Programmes for the Treatment of Conduct Disorder, Including Oppositional Defiant Disorder, in Children. West Midlands Health Technology Assessment Collaboration (WMHTAC), Department of Public Health and Epidemiology, The University of Birmingham (2004)

44. Department for Children, Schools and Families: Cost-Benefit Analysis of Interventions with Parents. Research Report DCSFRW0008 (2008)

45. Friedli, L., Parsonage, M.: Mental Health Promotion: building an Economic Case. Northern Ireland association for Mental Health, Belfast (2007)

46. Irish Prison Service Annual Report 2007: Available online at http://www.irishprisons.i.e/documents/IPS_AR_2007.pdf

47. Barnett, S.: Lives in the Balance: Age 27 Benefit Cost Analysis of the High/Scope Perry Preschool Program. High/Scope Educational Research Foundation Monograph No. 11, Ypsilanti, Michigan (1996)

48. Hutchings, J., Lane, E., Kelly, J.: Comparison of two treatments for children with severely disruptive behaviours: a four-year follow-up. Behav. Cogn. Psychother. 32, 15-30 (2004)

49. Webster-Stratton, C., Rinaldi, J., Reid, J.: Long-Term Outcomes of Incredible Years Parenting Program: Predictors of Adolescent Adjustment (2009). http://www.incredibleyears.com/library/items/ long-term-outcomes-of-iy-parenting-pgrm_7-7-09.pdf

50. McGilloway, S., Ni Mhaille, G., Furlong, M., Leckey, Y., Kelly, P., Bywater, T., Comiskey, C., Donnelly, M., O’Neill, D.: An Evaluation of the Longer-Term Effectiveness of the Incredible Years BASIC Parent Training Programme in Ireland: 12 Months Outcomes (2011)

51. Barnett, S.: Benefits of compensatory preschool education. J. Human Resour. 27(2), 279-312 (1992)

52. Heckman, J.R., LaLonde, Smith, J.: The economics and econometrics of active labour market programs. In: Ashenefelter, O., Card, D. (eds.) Handbook of Labour Economics (1999)

53. OECD: Education at a Glance 2009: OECD Indicator (2009). Available online at http://www.oecd.org/dataoecd/35/35/4361 8388.pdf 